\title{
Rhythmic variations in pain, stiffness, and manual dexterity in hand osteoarthritis
}

\author{
N Bellamy, R B Sothern, J Campbell, W W Buchanan
}

See end of article for authors' affiliations

.....................

Correspondence to: Professor N Bellamy, Centre of National Research on Disability and Rehabilitation Medicine (CONROD), Department of Medicine, Level 3, Mayne

Medical School, Herston

Road, Brisbane,

Queensland 4006,

Australia;

nbellamy@medicine.uq.edu.au

Accepted 2 May 2002

\begin{abstract}
Objective: To explore circadian variation in pain, stiffness, and manual dexterity in patients with hand osteoarthritis (OA).

Methods: Twenty one patients with hand OA, as defined by ACR criteria 117 women, four men, mean age 62.2 years, range $52-74$ years) self rated pain and stiffness on separate $10 \mathrm{~cm}$ horizontal visual analogue scales and performed bead intubation coordinometry $(\mathrm{BIC})$ six times each day (on waking up, at bedtime, and every four hours in between) for 10 consecutive days. Each series (using data with the trend removed if there was a significant trend) was analysed for circadian rhythmicity by a cosine vector technique (single cosinor). With individual data expressed as the percentage of the mean, group rhythm characteristics at period 24 hours were summarised for each variable by population mean cosinor analysis.

Results: Individual analyses identified significant circadian rhythms at $p \leqslant 0.05$ for pain $(n=15 / 21)$, stiffness $(n=16 / 20)$, and dexterity $(n=18 / 21)$, and a significant circadian rhythm on a group basis was identified for pain $(p=0.013)$, stiffness $(p<0.001)$, and dexterity $(p<0.001)$. Pain was least at 1610 and stiffness at 1618. Peak dexterity occurred in mid-afternoon at 1548 and occurred within the $95 \%$ confidence interval of least pain (1312-1800) and stiffness (1520-1732).

Conclusions: Dexterity was influenced by the patient's level of pain or stiffness, which changed systematically throughout the day. Similar results have been previously reported in 14 patients with rheumatoid arthritis where peak dexterity occurred at 1544 and at 1528 in 14 age and sex matched healthy controls. The predictability of rhythmic variation in pain, stiffness, and dexterity has implications for scheduling activities of daily living and for timing antirheumatic drug treatment.
\end{abstract}

C ircadian variation is common in biological systems. Plants, animals, and humans display rhythmic variation at various levels, from the cell to the entire organism. Rhythms that cycle about once a day are called circadian rhythms, ${ }^{1}$ those of higher or lower frequency being respectively termed ultradian and infradian rhythms. Several investigators have reported circadian variation in clinical and laboratory variables in patients with either inflammatory or degenerative disorders of the musculoskeletal system..$^{2-30}$ In general, these investigators have used traditional statistical methods to compare within-day variations. ${ }^{31}$ For some years, however, statistical methods based on least squares and cosine vector techniques, which permit the use of real time data, have been used successfully by chronobiologists in mapping the absolute and relative timing of different biological rhythms. ${ }^{32-34}$ We have used such techniques in successfully identifying circadian rhythms in pain, stiffness, and manual dexterity in rheumatoid arthritis (RA), ${ }^{2}$ and knee osteoarthritis (OA) pain. ${ }^{3}$ Circadian characteristics for these studies and more than 100 variables found in the literature that are pertinent to immune function and disease have been recently summarised in tables..$^{35}$ The identification of such rhythms has important implications for patients, both in planning their daily activities, and in developing individual therapeutic programmes in relation to circadian variability, which may be more effective (so-called "chronotherapy" programmes).

\section{MATERIALS AND METHODS}

A quasiexperimental one group repeated measures design was used. Patients were followed up for 10 consecutive days and made self measurements at home at prespecified time points. The protocol was approved by the University of Western Ontario review board for research involving human subjects.
Patients were recruited by telephone. Consenting outpatients with symptomatic hand $\mathrm{OA}$ in the dominant hand were enrolled in the study. To be eligible all patients had to be symptomatic - that is, to have had pain for at least three months in the dominant hand, fulfil American College of Rheumatology (ACR) classification criteria for hand $\mathrm{OA}^{36}$ be aged between 40 and 75 years, be capable of providing informed consent, be fluent in the English language, and, if taking NSAIDs, have reached a steady state (at least five days of treatment and would continue on the same agent for the duration of the study). Exclusion criteria were amputation of one or more digits, paralysis of either hand, comorbid condition causing pain, stiffness, or functional disability in the hands, pregnant or lactating women, prior orthopaedic surgery on either hand, concomitant musculoskeletal condition affecting the hands, patients requiring the use of narcotic class analgesics, unable to comprehend the visual analogue measurement scales (VAS) or perform bead intubation coordinometry (BIC) after adequate explanation, unavailable to perform self measurement for the next 10 days, requiring intra-articular steroid injections in the next 10 days, and starting physiotherapy in the next 10 days.

At baseline, data collected were age, sex, disease duration in the hands, hand dominance, ACR classification criteria, AUSCAN osteoarthritis hand index score, ${ }^{37}$ grip strength, ${ }^{38}$ pinch grip, distribution of hand involvement (for example,

Abbreviations: ACR, American College of Rheumatology; ANOVA analysis of variance; $\mathrm{BIC}$, bead intubation coordinometry; $95 \% \mathrm{Cl}, 95 \%$ confidence interval; OA, osteoarthritis; NSAIDs, non-steroidal anti-inflammatory drugs; RA, rheumatoid arthritis; ROC, range of change; VAS, visual analogue scale 
homunculus), Doyle index, ${ }^{39}$ information on current drugs (for example, dose and schedule). Patients self measured pain, stiffness, and manual dexterity each day on waking up and bedtime and about every four hours in between (target times $1000,1400,1800,2200$ ). Patients were instructed specifically to look at a watch or clock and record the actual time (real time) at which they performed self measurement, as it was unlikely over the 10 day period that the measurements could be performed exactly at the time specified. The collection of real time data was critical to the success of the analysis because of the potentially dynamic fluctuation which could occur in the three variables. In reality, some self measurements were performed at nearly every hour of the day and night.

Pain was self rated on a $10 \mathrm{~cm}$ horizontal VAS with end markers outside of which were placed terminal descriptors $($ left $=$ no pain, right $=$ most severe pain $\mathrm{I}$ have ever had $) .{ }^{2}{ }^{3}$ Patients were instructed to rate the severity of the pain in their hand at the exact moment of measurement in response to the question, "How much pain are you currently experiencing due to osteoarthritis in your dominant hand?"

Stiffness was self rated on a $10 \mathrm{~cm}$ horizontal VAS with end markers, outside of which were placed terminal descriptors (left $=$ no stiffness, right $=$ most severe stiffness $\mathrm{I}$ have ever had). ${ }^{23}$ Patients were instructed to rate the severity of the stiffness in their hand at the exact moment of measurement in response to the question, "How much stiffness are you currently experiencing due to osteoarthritis in your dominant hand?"

Manual dexterity was measured using a device termed a bead intubation coordinometer (BIC, fig l). ${ }^{32}$ This consists of a shallow circular aluminium receptacle with a flat base (11.5 $\mathrm{cm})$ and a vertical side $(4.0 \mathrm{~cm})$. The top is closed by a Perspex lid, carrying at its centre, a hollow vertical $(8 \mathrm{~cm})$ stainless steel tube. The calibre of the tube is such that it will only accept a series of sand blasted stainless steel precision beads $(0.65 \times 0.48 \mathrm{~cm})$ when they are presented with their long axis exactly aligned with the axis of the tube. Twenty five such beads are placed in a shallow plastic bowl to one side (determined by hand dominance) of the coordinometer, and a precision stopwatch is placed on the other side at a distance comfortable to the patient. The test is started with the patient's dominant hand holding the first bead, while the nondominant hand is on the stopwatch. Simultaneously, the watch is started and bead intubation started. Thereafter, the beads are inserted as fast as possible, one by one, into the tube. Immediately after the insertion of the last bead, the non-dominant hand stops the watch. Patients were instructed that the beads were to be picked up, one at a time, and if a bead was dropped on the table or the floor, the test had to be restarted. The BIC instrument used in this study is a modification of one previously used by one of us (NB) in a field trial in northwest Greenland.$^{40}$ The modifications made were as follows: $(a)$ the base of the coordinometer was enlarged to allow the osteoarthritic hand a better grip, and $(b)$ the beads were sand blasted to allow a better grip when lifting them out of the bowl. Pilot studies with this instrument have suggested that a learning effect occurs in the first 48-72 hours, and that 25 beads produce satisfactory data without tiring the patient.

These exact instruments were used in our previous work on circadian rhythmicity in manual dexterity in patients with RA and proved to be entirely satisfactory. ${ }^{2}$ Subjects were instructed to complete the questionnaire and BIC at or near the time points indicated, and, in any event, record accurately the actual clock time when the observation was made. Subjects waking up after 1000 or going to bed before 2200 would sometimes have fewer than the six designated observation points each day.

Patients were requested to note at the end of the day, the time, dose, and brand of any analgesics taken for any purpose during that day.

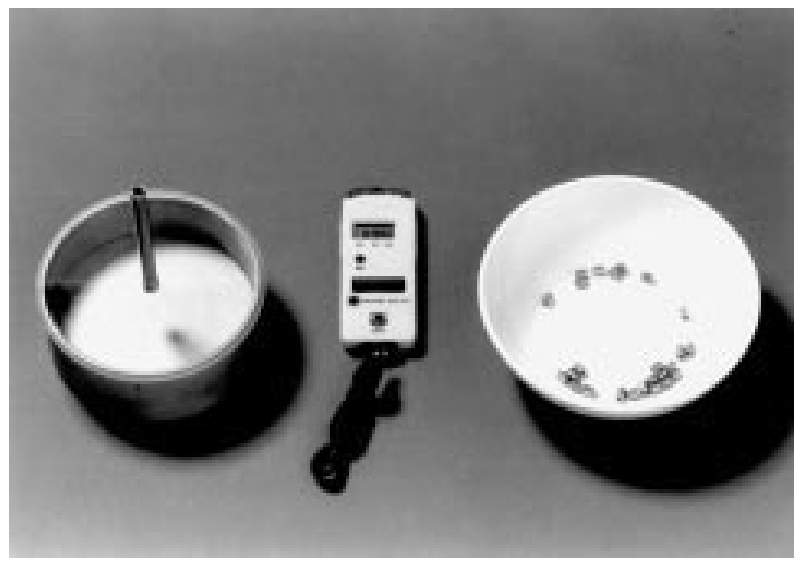

Figure 1 The bead intubation coordinometer.

Time series plots were constructed for each raw data series to view the data for patterns, trends, and outliers. No data were excluded from analysis. If any series showed a significant trend, the trend was statistically removed before analysis for time effects. Individual data series were converted to a percentage of the mean value before constructing overall waveforms for circadian frequencies for the three variables of interest and performing grouped time series analyses. ${ }^{33}{ }^{34} \mathrm{~A}$ one way analysis of variance (ANOVA) was used to test grouped data for the effect of time. Each series was analysed for circadian rhythmicity by the least squares method of fitting of cosines (single cosinor method ${ }^{33}$ ) with periods in the expanded circadian range 14-34 hours, ${ }^{41}$ and with 0.1 hours between trial periods. Group rhythm characteristics at precisely 2400 were summarised by population mean cosinor analysis. ${ }^{334}$ Rhythm detection was considered statistically significant for $\mathrm{p} \leqslant 0.05$ from a zero amplitude test and borderline significant for $0.05<p \leqslant 0.10$. Rhythm characteristics estimated from the single cosinor procedure included the mesor (middle of the fitted cosine, representing a rhythm adjusted mean when data are collected at uneven intervals), the amplitude (the distance from the mesor to the peak or trough (bathyphase) of the fitted cosine), and the acrophase (peak of the fitted cosine with reference to local midnight). Because our interest was in peak performance, results were expressed using the bathyphase rather than the acrophase, which is the clock time at which pain and stiffness are least and dexterity best. Correlations were also made between 24 hour averages (mesors) of each variable.

\section{RESULTS}

Twenty one patients ( 17 women and four men) with OA of the hand, as defined by the ACR criteria, provided data on self rated pain and stiffness and performed BIC over 10 days (table 1). Mean age was 62.2 years; range $52-74$ years. All patients were right handed. Mean grip strength for the dominant hand, over three attempts, was $156 \mathrm{~mm} \mathrm{Hg}$. The mean pinch grip for the dominant hand, over three attempts, was $4.7 \mathrm{~kg}$ (table 1).

The study was completed over a three month span, patients starting their data collection on different days of the week. All patients were in a steady state: three regularly receiving NSAIDs only, five receiving NSAIDs on a regular schedule and supplementary analgesia with acetaminophen as required, seven taking only analgesics on an "as required" basis, and six having neither NSAIDs nor analgesic treatment (table 1). None of the subjects were taking exogenous steroids for their arthritis or other comorbidities. All patients slept at night, with the average bedtime at 2330 (range 2100-0355) and waking up at 0730 (range 0415-1000). None of the 
Table 1 Demographic and disease characteristics

\begin{tabular}{|c|c|c|c|c|c|c|c|c|c|c|}
\hline \multirow[b]{2}{*}{ PIP } & \multirow[b]{2}{*}{ DIP } & \multirow[b]{2}{*}{$C M C$} & \multirow[b]{2}{*}{$\begin{array}{l}\text { Unilateral/ } \\
\text { Bilateral }\end{array}$} & \multirow[b]{2}{*}{ Patient } & \multirow[b]{2}{*}{ Sex } & \multirow[b]{2}{*}{ Age } & \multicolumn{2}{|c|}{ Dominant hand } & \multirow[b]{2}{*}{$\begin{array}{l}\text { NSAID } \\
\text { medication }\end{array}$} & \multirow[b]{2}{*}{$\begin{array}{l}\text { Analgesic } \\
\text { medication }\end{array}$} \\
\hline & & & & & & & $\begin{array}{l}\text { Mean grip } \\
\text { strength } \\
\text { (mm Hg) }\end{array}$ & $\begin{array}{l}\text { Mean pinch } \\
\text { strength } \\
(\mathrm{kg})\end{array}$ & & \\
\hline+ & + & - & B & $1 R$ & $\mathrm{~F}$ & 52 & 165 & 5.5 & $\mathrm{Nil}$ & $\mathrm{Nil}$ \\
\hline+ & - & + & B & $3 R$ & $\mathrm{~F}$ & 53 & 133 & 2.5 & Ibuprofen & $\mathrm{Nil}$ \\
\hline+ & + & + & B & $4 \mathrm{R}$ & $\mathrm{F}$ & 74 & 200 & 4.5 & Nyprosyn & Tylenol 2 \\
\hline+ & + & + & B & $5 R$ & $\mathrm{~F}$ & 62 & 206 & 4 & Ketoprofen & Nil \\
\hline+ & - & - & B & $6 R$ & $\mathrm{~F}$ & 54 & 123 & 1.8 & Nil & Tylenol 2 \\
\hline+ & + & + & B & $7 R$ & $\mathrm{~F}$ & 64 & 174 & 5.3 & Nil & Tylenol \\
\hline+ & + & - & B & $8 R$ & $\mathrm{~F}$ & 53 & 157 & 5.8 & Nil & $\mathrm{Nil}$ \\
\hline+ & + & + & B & $9 R$ & $\mathrm{~F}$ & 58 & 89 & 4.3 & Surgam & Tylenol \\
\hline+ & + & + & B & $10 R$ & $\mathrm{~F}$ & 69 & 130 & 3.7 & $\mathrm{Nil}$ & Tylenol \\
\hline+ & - & + & B & $11 R$ & $\mathrm{~F}$ & 62 & 94 & 3.7 & Nil & Tylenol \\
\hline+ & + & + & B & $15 R$ & $\mathrm{~F}$ & 69 & 103 & 4.2 & $\mathrm{Nil}$ & Tylenol \\
\hline+ & + & - & B & $16 R$ & $\mathrm{~F}$ & 69 & 160 & 4 & Nil & Tylenol \\
\hline+ & - & + & B & $17 R$ & $\mathrm{~F}$ & 66 & 187 & 4 & $\mathrm{Nil}$ & Nil \\
\hline+ & + & + & B & $18 R$ & $\mathrm{~F}$ & 58 & 87 & 4.8 & Arthrotec & Tylenol \\
\hline- & - & + & B & $19 R$ & $\mathrm{~F}$ & 57 & 187 & 3 & $\mathrm{Nil}$ & $\mathrm{Nil}$ \\
\hline+ & + & + & B & $20 R$ & $\mathrm{~F}$ & 59 & 43 & 1.7 & ASA & Tylenol 3 \\
\hline+ & + & + & B & $21 R$ & $\mathrm{~F}$ & 71 & 155 & 4.7 & Ibuprofen & None \\
\hline+ & + & + & B & $2 R$ & $M$ & 70 & 189 & 6.2 & Nil & $\mathrm{Nil}$ \\
\hline+ & + & + & B & $12 R$ & $M$ & 62 & 123 & 8.2 & Nil & Tylenol 3 \\
\hline+ & + & + & B & $13 R$ & $M$ & 71 & $300+$ & 9 & Flurbiprofen & Tylenol 3 \\
\hline+ & + & - & B & $22 R$ & $M$ & 53 & 273 & 8.8 & Nil & $\mathrm{Nil}$ \\
\hline
\end{tabular}

participants were involved in night work or shift work in the period of the study and none had indulged in transmeridional travel during the course of the study.

Figure 2 shows the overall circadian patterns for pain, stiffness, and dexterity along with the best fitting 24 hour cosine. From data normalised to percentage of the mean, a significant time effect was found by ANOVA for each variable at $p<0.001$ (table 2).

Pain scores varied from 0 to 93 and 24 hour mean pain values from 1.0 to 70.2 among 21 subjects. All subjects showed within 24 hour variability with a mean range of change (ROC) from lowest to highest values of 42.4 (individual ranges were from 4 to 82). On an individual basis, single cosinor analysis found a significant circadian rhythm at $p \leqslant 0.05$ for 15 subjects and at $0.05<\mathrm{p} \leqslant 0.10$ for 17 of the 21 subjects (table 3 ). Summary by population mean cosinor described a significant circadian rhythm for the group at $\mathrm{p}=0.013$, with an amplitude of $13 \%$ and the bathyphase at 1600 (table 2).

One subject failed to complete the stiffness scales. In the remaining 20 subjects, stiffness scores varied from 0 to 96 and
24 hour mean stiffness values from 4.8 to 78.9 . All 20 subjects showed within 24 hour variability with a mean ROC of 47.4 (individual ranges 9 to 85). On an individual basis, single cosinor analysis showed a significant circadian rhythm at $p \leqslant 0.05$ for 16 out of 20 subjects (table 3 ). Summary by population mean cosinor showed a significant circadian rhythm for the group at $p<0.001$, with an amplitude of $22 \%$ and the bathyphase at 1618 (table 2).

Bead intubation times varied from 40 to 190 seconds and 24 hour mean BIC values varied from 47.1 to 109.0 seconds among 21 subjects. All subjects showed within 24 hour variability with a mean ROC of 46.8 (individual ranges were from 10 to 118 seconds). On an individual basis, single cosinor analysis found a significant circadian rhythm at $p \leqslant 0.05$ for 18 subjects and at $0.05<\mathrm{p} \leqslant 0.10$ for 20 of the 21 subjects (table 3 ). Summary by population mean cosinor described a significant circadian rhythm for the group at $\mathrm{p}<0.001$, with an amplitude of $8 \%$ and the bathyphase at 1548 (table 2).

The 24 hour means (mesors) for pain and stiffness showed a positive correlation between each other $(r=0.76, \mathrm{p}<0.001)$,
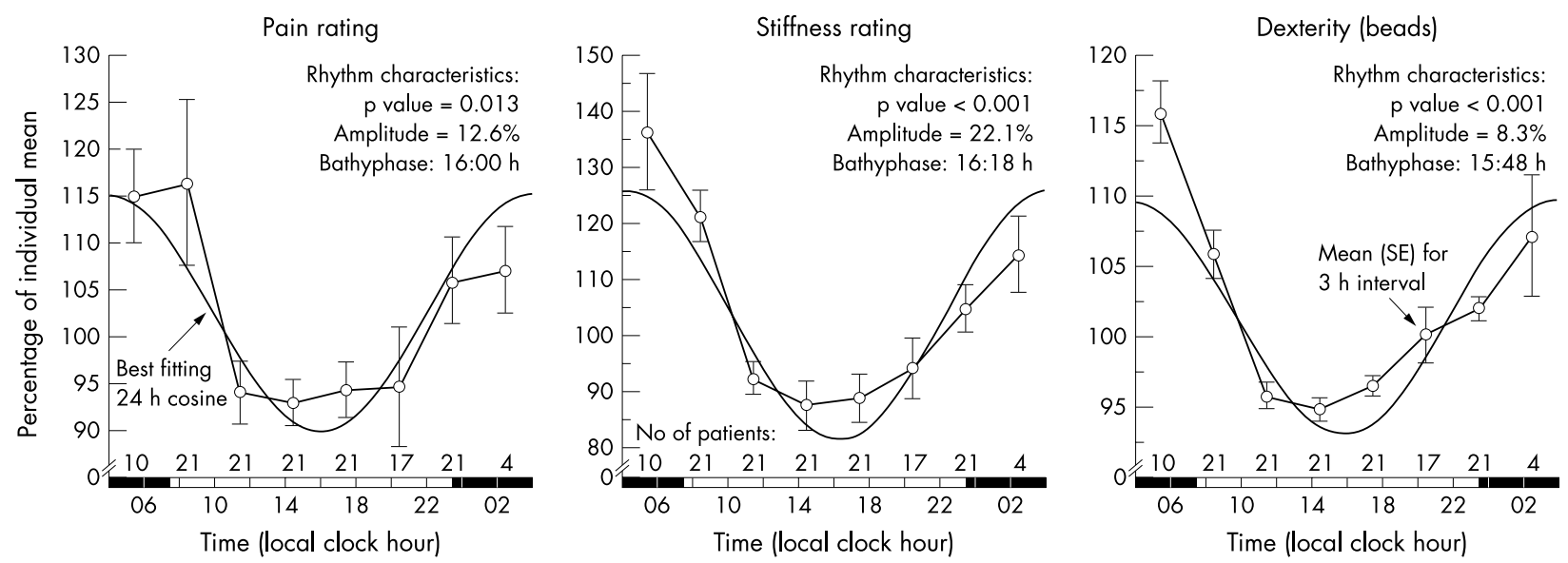

Figure 2 Circadian rhythm for pain, stiffness, and dexterity in patients with osteoarthritis of the hand. Self measurements/ratings were made by 20 or 21 patients every 24 hours during waking for 10 days. Individual values had trends removed and were converted to a percentage of the mean before combining for group analysis by population mean cosinor. For rhythm characteristics $p$ value is from the zero amplitude test; amplitude=half peak trough difference of cosine; bathyphase=lowest point of cosine (referenced from 0000). $p$ Values $<0.001$ for each variable from ANOVA for time effect. 
Table 2 Group circadian rhythm characteristics for pain rating, stiffness rating, and dexterity

\begin{tabular}{|c|c|c|c|c|c|c|c|c|c|c|c|c|c|c|c|c|c|}
\hline \multirow{3}{*}{\multicolumn{2}{|c|}{ Time effect: }} & \multicolumn{16}{|c|}{ Units analysed: } \\
\hline & & \multicolumn{8}{|c|}{ Original } & \multicolumn{8}{|c|}{$\%$ of mean } \\
\hline & & \multicolumn{2}{|c|}{ ANOVA } & \multicolumn{6}{|c|}{ Cosine period $=24.0 \mathrm{~h}$} & \multicolumn{2}{|c|}{ ANOVA } & \multicolumn{6}{|c|}{ Cosine period $=24.0 \mathrm{~h}$} \\
\hline Variable & $\mathrm{n}$ & $\mathrm{F}$ & $p$ Value & $\mathrm{p}$ Value & $M(S E)$ & $A(S E)$ & $(\% A)$ & $b \varnothing(h)$ & $95 \% \mathrm{Cl}(\mathrm{h})$ & $\mathrm{F}$ & $\mathrm{p}$ Value & $\mathrm{p}$ Value & $M(S E)$ & $A(S E)$ & $(\% A)$ & $b \varnothing(h)$ & $95 \% \mathrm{Cl}(\mathrm{h})$ \\
\hline & 21 & 1.4 & 0.217 & 0.021 & $31.2(5.3)$ & $2.9(1.1)$ & (9) & $16: 50$ & $(12: 28$ to $18: 56)$ & 4.6 & $<0.001$ & 0.013 & $102(1)$ & $13(4)$ & (12) & $16: 00$ & (13:12 to $18: 00)$ \\
\hline Stiffness & 20 & 5.4 & $<0.001$ & $<0.001$ & $37.6(5.3)$ & $6.7(1.3)$ & (18) & $16: 13$ & $(15: 08$ to $17: 16)$ & 22.2 & $<0.001$ & $<0.001$ & 104 (1) & $22(4)$ & (21) & $16: 18$ & (15:20 to $17: 32)$ \\
\hline $\mathrm{BIC}$ & 21 & 9.4 & $<0.001$ & $<0.001$ & $75.9(3.6)$ & $6.4(0.9)$ & (8) & 15:41 & (14:56 to $16: 24)$ & 44.2 & $<0.001$ & $<0.001$ & $101(0)$ & $8(1)$ & (8) & $15: 48$ & (15:00 to $16: 28)$ \\
\hline
\end{tabular}

Data obtained by self measurement every $2-4 \mathrm{~h}$ during waking only for 10 days. Any series with a significant trend had the trend removed before analysis for circadian rhythm by the least squares fit of a $24.0 \mathrm{~h}$ cosine. Circadian characteristics $(M, A, b \varnothing)$ summarised by population mean cosinor analysis.

For rhythm characteristics: p value from zero amplitude test; $M=$ mesor (middle value of fitted cosine); $A=$ amplitude (distance from $M$ to peak or trough of cosine); \% $=\%$ amplitude (A as \% of $M$ ); $\varnothing \varnothing=$ bathyphase (lowest point of fitted cosine, referenced from 00:00 h); ANOVA = analysis of variance across six 4 hourly intervals.

Table 3 Individual circadian rhythm characteristics for pain rating, stiffness rating, and dexterity

\begin{tabular}{|c|c|c|c|c|c|c|c|c|c|c|c|c|c|c|c|c|c|c|c|c|c|c|}
\hline \multirow{4}{*}{$\begin{array}{l}\text { Patient/ } \\
\text { sex }\end{array}$} & \multirow[b]{4}{*}{$\mathrm{N}$} & \multicolumn{21}{|l|}{ Variable: } \\
\hline & & \multicolumn{5}{|c|}{ Pain rating } & \multicolumn{2}{|c|}{ Best fitting } & \multicolumn{5}{|c|}{ Stiffness rating } & \multicolumn{2}{|c|}{ Best fitting } & \multicolumn{5}{|l|}{ Dexterity } & \multicolumn{2}{|c|}{ Best fitting } \\
\hline & & \multicolumn{5}{|c|}{ Fitted period $=24.0 \mathrm{~h}$} & \multicolumn{2}{|c|}{ Circadian period } & \multicolumn{5}{|c|}{ Fitted period $=24.0 \mathrm{~h}$} & \multicolumn{2}{|c|}{ Circadian period } & \multicolumn{5}{|c|}{ Fitted period $=24.0 \mathrm{~h}$} & \multicolumn{2}{|c|}{ Circadian period } \\
\hline & & $\mathrm{p}$ Value & M & A & (\%A) & $b \varnothing(h)$ & Hours & $\mathrm{p}$ Value & $p$ Value & M & A & $(\% \mathrm{~A})$ & $\mathrm{b} \varnothing(\mathrm{h})$ & Hours & $\mathrm{p}$ Value & $\mathrm{p}$ Value & M & A & $(\% \mathrm{~A})$ & $b \varnothing(h)$ & Hours & $\mathrm{p}$ Value \\
\hline $1 \mathrm{~F}$ & 60 & 0.150 & 14.2 & 5.1 & (36) & $15: 42$ & 23.9 & 0.147 & $<0.001$ & 18.9 & 14.0 & $(74)$ & $15: 44$ & 24.1 & $<0.001$ & $<0.001$ & 70.2 & 6.5 & (9) & $15: 36$ & 23.7 & $<0.001$ \\
\hline $3 \mathrm{~F}$ & 49 & $<0.001$ & 67.7 & 7.8 & (12) & 07:08 & 23.8 & $<0.001$ & $<0.001$ & 48.0 & 18.2 & (38) & $16: 14$ & 24.2 & $<0.001$ & $<0.001$ & 55.4 & 6.4 & (12) & $16: 37$ & 23.8 & $<0.001$ \\
\hline $4 \mathrm{~F}$ & 60 & 0.020 & 2.2 & 1.3 & (60) & $17: 18$ & 24.3 & 0.012 & 0.015 & 12.6 & 4.2 & (34) & $17: 59$ & 24.6 & 0.001 & $<0.001$ & 67.3 & 8.2 & (12) & $15: 55$ & 24.0 & $<0.001$ \\
\hline $5 \mathrm{~F}$ & 52 & 0.786 & 2.3 & 0.1 & (5) & $05: 12$ & 22.3 & 0.049 & 0.041 & 5.0 & 1.1 & $(21)$ & $15: 50$ & 24.5 & 0.012 & 0.022 & 64.3 & 4.2 & (7) & $15: 02$ & 24.7 & $<0.001$ \\
\hline $6 \mathrm{~F}$ & 44 & 0.035 & 21.2 & 7.7 & (36) & $13: 10$ & 24.1 & 0.035 & 0.005 & 38.7 & 17.6 & (45) & $15: 42$ & 23.4 & $<0.001$ & 0.259 & 113.8 & 13.0 & (11) & $14: 49$ & 23.7 & 0.224 \\
\hline $7 F$ & 60 & 0.214 & 3.5 & 0.9 & (27) & $12: 44$ & 23.2 & 0.057 & 0.327 & 71.3 & 1.0 & (1) & $17: 52$ & 20.9 & 0.112 & 0.323 & 70.8 & 2.7 & (4) & $17: 03$ & 21.6 & 0.045 \\
\hline $8 \mathrm{~F}$ & 59 & 0.191 & 6.0 & 0.4 & (7) & $12: 02$ & 23.0 & 0.124 & 0.721 & 8.0 & 0.2 & (3) & $10: 38$ & 26.8 & 0.330 & $<0.001$ & 47.1 & 1.7 & (4) & $09: 30$ & 23.5 & $<0.001$ \\
\hline $9 \mathrm{~F}$ & 46 & 0.007 & 61.7 & 6.2 & (10) & $17: 02$ & 23.8 & 0.005 & 0.126 & 79.6 & 4.4 & (6) & $14: 46$ & 24.7 & 0.017 & $<0.001$ & 64.3 & 7.7 & (12) & $16: 05$ & 24.0 & $<0.001$ \\
\hline $10 \mathrm{~F}$ & 60 & 0.138 & 9.1 & 2.7 & (30) & $16: 51$ & 23.6 & 0.100 & 0.042 & 17.9 & 5.2 & (29) & $14: 48$ & 22.8 & 0.003 & $<0.001$ & 95.2 & 10.4 & (11) & $15: 04$ & 23.8 & $<0.001$ \\
\hline $11 \mathrm{~F}$ & 60 & $<0.001$ & 48.8 & 15.8 & (32) & $20: 32$ & 24.2 & $<0.001$ & $<0.001$ & 40.0 & 10.7 & (27) & $18: 48$ & 24.2 & $<0.001$ & $<0.001$ & 75.3 & 10.2 & (14) & $17: 15$ & 24.3 & $<0.001$ \\
\hline $15 \mathrm{~F}$ & 48 & $<0.001$ & 40.6 & 13.6 & (34) & $18: 34$ & 23.9 & $<0.001$ & 0.011 & 50.0 & 13.2 & (26) & $18: 26$ & 25.2 & $<0.001$ & $<0.001$ & 57.9 & 7.3 & (13) & $17: 22$ & 24.1 & $<0.001$ \\
\hline $16 \mathrm{~F}$ & 58 & 0.367 & 36.1 & 1.9 & (5) & $01: 53$ & 21.8 & 0.013 & - & - & - & - & - & - & - & 0.102 & 77.7 & 1.8 & (2) & $14: 02$ & 22.4 & 0.011 \\
\hline $17 \mathrm{~F}$ & 56 & 0.303 & 13.7 & 2.2 & (16) & $22: 44$ & 24.6 & 0.252 & 0.219 & 12.3 & 2.4 & (19) & $23: 33$ & 24.8 & 0.110 & 0.088 & 71.9 & 2.3 & (3) & $09: 38$ & 23.6 & 0.069 \\
\hline $18 \mathrm{~F}$ & 43 & 0.050 & 52.0 & 8.1 & (15) & $13: 30$ & 23.6 & 0.023 & $<0.001$ & 43.0 & 13.5 & (31) & 13:33 & 24.1 & $<0.001$ & 0.002 & 102.0 & 17.8 & (17) & $14: 54$ & 24.1 & 0.002 \\
\hline $19 \mathrm{~F}$ & 50 & 0.200 & 11.0 & 2.7 & (24) & $10: 15$ & 23.2 & 0.128 & 0.006 & 17.5 & 5.7 & (32) & $14: 19$ & 23.7 & 0.002 & 0.095 & 81.6 & 7.0 & (9) & $15: 02$ & 23.2 & 0.005 \\
\hline $20 \mathrm{~F}$ & 52 & 0.002 & 71.1 & 7.8 & (11) & $10: 14$ & 24.5 & $<0.001$ & 0.005 & 72.7 & 6.3 & (9) & $11: 56$ & 24.6 & $<0.001$ & 0.042 & 103.6 & 5.9 & (6) & $11: 22$ & 23.3 & 0.030 \\
\hline $21 \mathrm{~F}$ & 60 & $<0.001$ & 66.2 & 16.6 & (25) & $18: 01$ & 23.8 & $<0.001$ & $<0.001$ & 60.3 & 14.1 & (23) & $17: 39$ & 23.7 & $<0.001$ & $<0.001$ & 76.4 & 11.6 & (15) & $17: 46$ & 24.0 & $<0.001$ \\
\hline $2 M$ & 60 & 0.022 & 45.8 & 4.0 & (9) & $20: 42$ & 23.4 & 0.014 & 0.215 & 52.1 & 4.4 & (8) & $16: 24$ & 23.8 & 0.200 & 0.159 & 82.7 & 4.7 & (6) & $15: 16$ & 23.1 & 0.050 \\
\hline $12 M$ & 60 & 0.020 & 49.2 & 3.1 & (6) & $18: 10$ & 23.7 & 0.017 & $<0.001$ & 59.8 & 10.0 & (17) & $16: 27$ & 23.9 & $<0.001$ & $<0.001$ & 73.4 & 8.1 & (11) & $16: 18$ & 23.8 & $<0.001$ \\
\hline $13 M$ & 60 & 0.088 & 27.2 & 4.4 & $(16)$ & $14: 46$ & 24.8 & 0.002 & 0.034 & 30.0 & 5.2 & (17) & $14: 43$ & 24.8 & $<0.001$ & 0.162 & 67.7 & 2.6 & (4) & $14: 39$ & 26.9 & 0.059 \\
\hline $22 M$ & 55 & 0.790 & 5.6 & 0.7 & (12) & $07: 32$ & 32.3 & 0.023 & 0.049 & 13.8 & 4.3 & (31) & $19: 27$ & 23.5 & 0.022 & $<0.001$ & 76.4 & 7.1 & (9) & $17: 28$ & 23.8 & $<0.001$ \\
\hline
\end{tabular}

Data obtained by self measurement every $2-4 \mathrm{~h}$ during waking only for 10 days. Any series with a significant trend had the trend removed before analysis for circadian rhythm by the least squares fit of a $24.0 \mathrm{~h}$ cosine. Each series was also analysed for best fitting cosine in the circadian domain between 14 and $34 \mathrm{~h}$.

For rhythm characteristics: $p$ value from zero amplitude test; $M=$ =mesor (middle value of fitted cosine); $A=a m p l i t u d e$ (distance from $M$ to peak or trough of cosine); \%A=\% amplitude (A as \% of $M$ ); $\varnothing \varnothing=$ bathyphase (lowest point of fitted cosine, referenced from 00:00h) 
indicating that these two measures were proportional within each patient (for example, as one rating increased, so did the other). There was also an inverse correlation between rhythm detection $\mathrm{p}$ values and the mesor for pain $(r=-0.58, \mathrm{p}=0.006)$ and stiffness $(r=-0.56, p=0.010)$, indicating the likelihood of an increased chance of rhythm detection with increasing levels of either of these two ratings (for example, a lower $p$ value was obtained when pain or stiffness were more severe).

\section{DISCUSSION}

Pain, stiffness, and physical function are important measures of hand OA. In this study we used conventional $10 \mathrm{~cm}$ visual analogue scales to measure pain and stiffness, and a novel instrument (BIC), not previously used in the assessment of patients with hand OA. Performance using the BIC may be altered by the presence of musculoskeletal or neurological disease. However, the patients in this study had no clinical evidence of neurological disease, and thus performance decrements were attributable to the presence of articular disease. As such, BIC became a measure of dominant hand dexterity.

In this study we mapped daily changes in pain, stiffness, and BIC in a group of patients with OA who are typical of those recruited for NSAID studies. It is of note that variability in most, but not all, patients with OA was not random but instead showed a significant adherence to a quasisinusoidal rhythm having a period of about 24 hours. The data suggest that the level of pain, stiffness, and dexterity throughout the day are in part predictable. Furthermore, we noted that dexterity is best about the time that pain and stiffness are least-that is, in the late afternoon.

Analgesic usage data were not interpretable and Environment Canada statistics on temperature and humidity were not obtained. We recognise that the modulating effects of these variables on circadian variation cannot be fully dissected without such information. However, in a previous study of circadian and circaseptan rhythms in pain perception in knee OA we were unable to show any significant relation between fluctuations in pain scores and either analgesic consumption or the aforementioned biometeorological factors. ${ }^{3}$

We have two prior experiences of using BIC measurement. The first was in a study of 12 medical students in northwest Greenland.$^{40}$ In that study no significant rhythm was detected in BIC, but the field conditions were severe with low ambient temperature, dry skin, and the polished surface of the beads contributing to the difficulty of performing the task. We think that sand blasting the beads was a major contribution to our success in detecting rhythmicity in this study. Our second experience was in hand RA where we noted that manual dexterity in healthy controls was characterised by a rhythm of lower level and smaller amplitude than in patients with RA. ${ }^{2}$ The lower level was accounted for by the faster speed at which healthy subjects completed the task. The smaller amplitude was probably due to the absence of the modulating influences of pain, stiffness, and other aspects of the inflammatory process, which may have made it more difficult for patients with RA to perform BIC at some times of day than others. Because peak dexterity in patients with RA and controls occurred at almost the same time, we postulated that the dexterity profile of patients with RA merely represented a vertical distortion of the normal dexterity rhythm found in healthy controls, and that the distortion might have been mediated by the modulating influences of joint pain and stiffness. In the OA study reported here, we have also found synchronicity between pain, stiffness, and dexterity rhythms. While recognising the limitations of interstudy comparisons, it is of note that peak dexterity in hand OA (1548), RA (1544), and healthy controls (1528) in the two studies occurred within 20 minutes of one another. This reinforces the contention that arthritis symptoms of pain and stiffness vertically distort the level of performance, but do not horizontally distort the normal phase of the dexterity rhythm.

There are three ways in which the results of this study may find practical application. Firstly, as most subjects show circadian rhythmicity in manual dexterity, and this is consistent from day to day, patients with hand OA may find advantage in planning those activities requiring manual dexterity during the period of the day when manual dexterity is least affected by their arthritis. Secondly, in clinical trials, knowledge of circadian rhythmicity in pain, stiffness, and dexterity can be used to inform protocol development, and both the scheduling and structuring of assessments for these three variables. Finally, the existence of circadian rhythmicity may provide an opportunity for an approach to treatment with analgesic and anti-inflammatory class compounds, using the principles of chronotherapy, where the pharmacokinetic and pharmacodynamic properties of compounds are viewed in the context of circadian rhythmicity, to optimally time drug treatment at an individual patient level. This approach merits formal evaluation using appropriately selected pharmaceutical drugs, and patients showing circadian rhythmicity in pain.

We conclude that pain, stiffness, and dexterity show circadian rhythmicity in hand OA. Assuming that these findings are generalisable to the OA hand population as a whole, there are important implications for scheduling activities of daily living, for measurement in clinical trials, and possibly for the time at which antirheumatic drugs are given.

\section{ACKNOWLEDGEMENT}

We acknowledge the contributions by Dr Elaine Soucy and Ms Jennifer Flynn to the data collection phase of this study.

\section{Authors' affiliations}

N Bellamy, Centre of National Research on Disability and Rehabilitation Medicine (CONROD), University of Queensland, Brisbane, Australia R B Sothern, Chronobiometry, College of Biological Sciences, University of Minnesota, Minneapolis, USA

J Campbell, Department of Surgery, University of Western Ontario, London, Canada

W W Buchanan, Department of Medicine, McMaster University, Hamilton, Canada

\section{REFERENCES}

1 Halberg F, Carandente G, Cornelissen G, Katinas G. Glossary of chronobiology. Chronobiologia 1977;4(suppl 1):1-89.

2 Bellamy N, Sothern RB, Campbell J, Buchanan WW. Circadian rhythm in pain, stiffness, and manual dexterity in rheumatoid arthritis: relation between discomfort and disability. Ann Rheum Dis 1991;50:243-8.

3 Bellamy N, Sothern RB, Campbell J. Rhythmic variations in pain perception in osteoarthritis of the knee. J Rheumatol 1990; 17:364-72.

4 Levi F, Le Louarn C, Reinberg A. Chronotherapy of osteoarthritic patients: optimization of indomethacin sustained release (ISR). In: Reinberg A, Smolensky M, Labrecque G, eds. Annual review of chronopharmacology. Oxford: Pergamon Press, 1984;1:345-8.

5 Levi F, Le Louarn C, Reinberg A. Timing optimizes sustained-release indomethacin treatment of osteoarthritis. Clin Pharmacol 1985;37:77-84

6 Levi F. Chronobiology and the treatment of rheumatologic disorders Monograph on rheumatology. Montreal: Merck, Sharp and Dohme Canada, 1986

7 Levi F, Le Louarn C, Simon L, Peltier A, Reinberg A. Chronotherapy of osteoarthritic patients with sustained-release preparation of indomethacin (ISR): group and individualized drug optimization. Chronobiologia 1983;10:139.

8 Clench J, Reinberg A, Dziewanowska Z, Ghata J, Smolensky M. Circadian changes in the bioavailability and effects of indomethacin in healthy subjects. Eur J Clin Pharmacol 1981;20:359-69.

9 Petersen I, Baatrup G, Brandslund I, et al. Circadian and diurnal variation of circulating immune complexes, complement-mediated solubilization, and the complement split product $\mathrm{C} 3 \mathrm{~d}$ in rheumatoid arthritis. Scand J Rheumatol 1986;15:113-8.

10 Sitton NG, Taggart AJ, Dixon JS, Surrall KE, Bird HA. Circadian variation in biochemical assessments used to monitor rheumatoid arthritis. Ann Rheum Dis 1984;43:444-50.

11 Robertson JC, Helliwel MG, Cantrell EG, Cawley MID, Ellis RM. Circadian variation in disease activity in rheumatoid arthritis. BM 1982;284:1114-5. 
12 Swannell AJ. Biological rhythms and their effect in the assessment of disease activity in rheumatoid arthritis. British Journal of Clinical Practice 1984; (suppl 33): 16-9.

13 Harkness JAL, Richter MB, Panayi GS, Van de Pette K, Unger A, Pownall $R$, et al. Circadian variation in disease activity in rheumatoid arthritis. Ann Rheum Dis 1980;39:529.

14 Harkness JAL, Richter MB, Panayi GS, Van de Pette K, Unger A, Pownall $R$, et al. Circadian variation in disease activity in rheumatoid arthritis. BM 1982;284:551-4.

15 Kowanko IC, Knapp MS, Pownall R, Swannell AJ. Domiciliary self-measurement in rheumatoid arthritis and the demonstration of circadian rhythmicity. Ann Rheum Dis 1982;41:453-5

16 Kowanko IC, Pownall R, Knapp MS, Swannell AJ, Mahoney PG. Circadian variations in the signs and symptoms of rheumatoid arthritis and in the therapeutic effectiveness of flurbiprofen at different times of day. Br J Clin Pharmacol 1981;11:477-84.

17 Kowanko IC, Pownall R, Knapp MS, Swannell AJ, Mahoney PG. Time of day of prednisolone administration in rheumatoid arthritis. Ann Rheum Dis 1982;41:447-84.

18 Wright V. Some observations on diurnal variation of grip. Clin Science 1959:18:17-23

19 Gunther R, Herold M, Halberg E, Halberg F. Circadian placebo and ACTH effects on urinary cortisol in arthritis. Peptides 1980;1:387-90

20 Knapp MS. Chronobiology: a subject of importance to the rheumatologist? British Journal of Clinical Practice 1984;1-7.

21 Heyman ER. Variability of proximal interphalangeal joint size measurements in normal adults. Arthritis Rheum 1974;17:79-84.

22 Pownall R, Pickvance NJ. Does treatment timing matter? A double blind crossover study of ibuprofen $2400 \mathrm{mg}$ per day in different dosage schedules in treatment of chronic low back pain. British Journal of Clinical Practice 1985;39:267-75

23 Pownall R. Biological rhythms in cell-mediated immunity; their relevance in rheumatology. British Journal of Clinical Practice 1984; (suppl 33):20-3.

24 Unger A. Biological rhythms in the humoral immune system; their possible significance in rheumatology. British Journal of Clinical Practice 1984; (suppl 33):24-7.

25 Smolensky M, D'Alonzo GE. Biologic rhythms and medicine. Am J Med 1988;85:34-46

26 Smolensky M. Aspects of human chronopathology. In: Schafer KE, eds. Topics in environmental physiology and medicine. New York: Springer-Verlag, 1983:131-209.
27 Brothers GB Jr, Hadler NM. Diurnal variations in rheumatoid synovia effusions. J Rheumatol 1983;10:471-4

28 Kotulska AT, Brzezinska-Wcislo L, Kucharz EJ. Circadian profile of serum melatonin in patients with systemic sclerosis. Ann Rheum Dis 2001;60(suppl I): 198.

29 Hrycaj P, Kelemen J, Stratz T, Muller W. The 24-hr urinary excretion of 6-sulphatoxymelantonin and 5-hydroxyindoleacetic acid in women with primary fibromyalgia and chronic low back pain. Ann Rheum Dis 2001;60(suppl I):250-1.

30 Dessein PH, Stanwix AE, Moomal Z. Predictors of pain and its change over time in fibromyalgia. Ann Rheum Dis 2001;60(suppl I):248.

31 Colton T. Statistics in medicine. Boston: Little, Brown; 1974.

32 Halberg F, Johnson EA, Nelson W, Runge W, Sothern RB. Autorhythmometry-procedures for physiologic self-measurements and their analysis. Physiological Teacher 1972;1:1-11

33 Nelson W, Tong YL, Lee JK, Halberg F. Methods for cosinor-rhythmometry. Chronobiologia 1979:6:305-23.

34 DePrins J, Cornelissen G, Malberg W. Statistical procedures in chronobiology and chronopharmacology. In: Reinberg A, Smolensky M, Labrecque G, eds. Annual review of chronopharmacology 2. Oxford: Pergamon Press, 1986:27-141.

35 Sothern RB, Roitman-Johnson B. Biological rhythms and immune function. In: Ader R, Felten DL, Cohen N, eds. Psychoneuroimmunology. 3rd ed. Vol 1. San Diego: Academic Press, 2001:445-79.

36 Altman RD. Criteria for classification of clinical osteoarthritis. J Rheumatol 1991;18(suppl 27):10-2.

37 Bellamy N, Haraoui B, Buchbinder R, Hall S, Muirden K, Roth J, et al. Development of a disease-specific health status measure for hand osteoarthritis clinical trials. I. Assessment of the symptom dimensionality. Scand J Rheumatol 1996;Suppl 106:5.

38 Bellamy N. Mechanical and electromechanical devices. Musculoskeletal clinical metrology. Dordrecht: Kluwer Academic Publishers, 1993: 117-34.

39 Doyle DV, Dieppe PA, Scott J, Huskisson EC. An articular index for the assessment of osteoarthritis. Ann Rheum Dis 1981:40:75-8.

40 Simpson H, Bellamy N, Bohlen J, Halberg F. Double blind trial of a possible chronobiotic (Quiadon); field studies in NW Greenland. International Journal of Chronobiology 1973;1:287-31 1

41 Hassnaoui M, Pupier R, Attia J, Blanc M, Beauchaud M, Buisson B. Some tools to analyze changes of rhythms in biological time series. Biological Rhythm Research 1998;29:353-66.

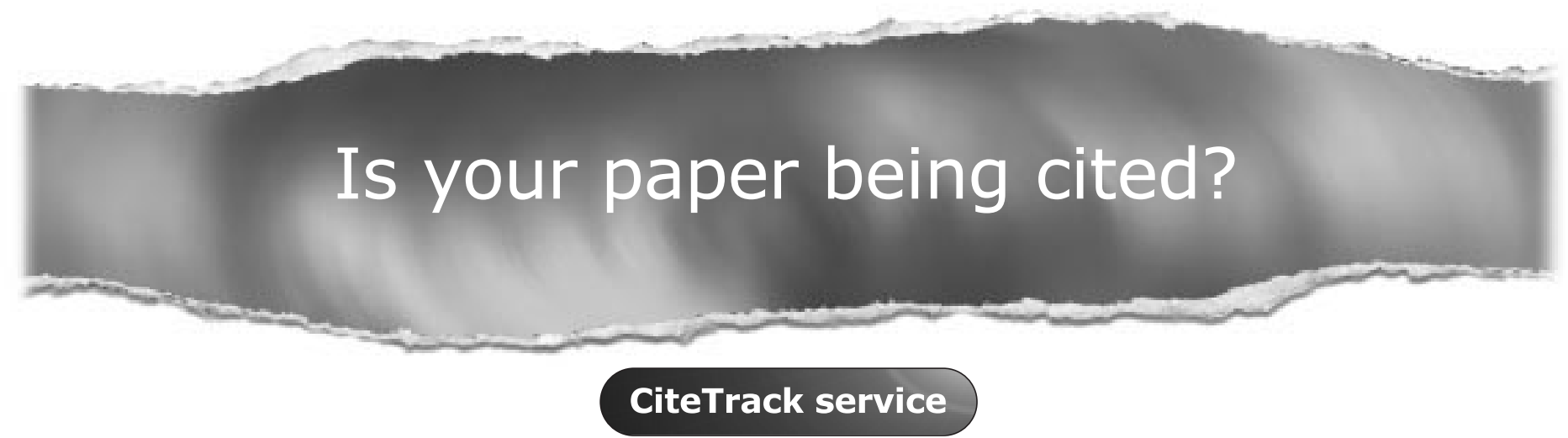

CiteTrack will alert you by email whenever new content in Annals of the Rheumatic Diseases or a participating journal is published

that matches criteria you want to track

Topics: Tell CiteTrack which words or subjects to watch for in new content

Authors: Be alerted whenever key authors you are following publish a new paper

Articles: Know whenever a paper of interest to you is referenced by another paper

www.annrheumdis.com 